\title{
A caminho de um estado de bem-estar social na China? Uma análise a partir dos sistemas de saúde e de educação *
}

\author{
Isabela Nogueira ${ }^{* * * * * *}$ \\ Fabianna Bacil ${ }^{* * * *}$ \\ João Victor Guimarães ${ }^{* * * * * * * * * * * *}$
}

\begin{abstract}
Resumo
Este artigo oferece uma caracterização detalhada do sistema de proteção social na China com foco nos sistemas públicos de saúde e de educação, descrevendo as reformas, os programas implementados, os resultados alcançados e seus principais problemas no período entre 1980 e 2015. A análise utiliza os sistemas de saúde e de educação como proxy do Estado de bem-estar social que se desenha na China desde a virada do século, visto que reformas similares têm sido levadas a cabo em outras áreas, como no mercado de trabalho e na previdência. Este artigo realiza ainda uma comparação qualitativa com as tipologias de regimes de bem-estar social desenvolvidas pela literatura tanto para países ocidentais quanto para países do leste asiático.
\end{abstract}

Palavras-chave: China; Estado de bem-estar social; Saúde; Educação; Proteção Social.

\section{Abstract}

\section{Is China heading toward a Welfare State? An analysis based on the health and education systems}

This article presents a detailed description of the Chinese welfare system, focusing our analysis on the public healthcare and education systems. It scrutinizes the main reforms and the implemented programs and analyzes some of the results and the most significant problems in the period from 1980 to 2015. The healthcare and education systems are used as a proxy for the Chinese welfare system, since similar reforms have taken place in other areas, such as in the labor market and in pension schemes. We also make a qualitative comparison with the most important welfare typologies that are used in the literature to study Western countries and some selected East Asian states.

Keywords: China; Welfare state; Healthcare; Education; Social protection.

JEL I00, I31, I38, O53.

\section{Introdução}

Em tempos de crise e de questionamentos ao papel do Estado na provisão de bem-estar social no Brasil e no mundo, experiências comparadas, sobretudo de outras grandes nações em

\footnotetext{
* Artigo recebido em 5 de julho de 2018 e aprovado em 3 de fevereiro de 2019.

${ }^{* *}$ Professora do Instituto de Economia da Universidade Federal do Rio de Janeiro (IE. UFRJ), Rio de Janeiro, RJ, Brasil. E-mail: isabela.nogueira@ie.ufrj.br. ORCID: https://orcid.org/0000-0001-8223-7906.

*** Coordenadora do Laboratório de Estudos em Economia Política da China da Universidade Federal do Rio de Janeiro (LabChina. URRJ), Rio de Janeiro, RJ, Brasil.

${ }_{* * * *}^{*}$ Pesquisadora no International Policy Centre for Inclusive Growth - United Nations Development Programme (UNDP), Brasília, DF, Brasil. E-mail: fbacil.ferreira@gmail.com. ORCID: http://orcid.org/0000-0003-2968-3688.

${ }^{* * * * * *}$ Doutorando do Programa de Pós-Graduação em Economia Política Internacional da Universidade Federal do Rio de Janeiro (UFRJ), Rio de Janeiro, RJ, Brasil. E-mail: jvictorguimaraes@ ufrj.br. ORCID: https://orcid.org/0000-0003-3269-6105.

${ }^{* * * * * * *}$ Pesquisador do Laboratório de Estudos em Economia Política da China da Universidade Federal do Rio de Janeiro (LabChina. URRJ), Rio de Janeiro, RJ, Brasil.
} 
desenvolvimento, tornam-se especialmente relevantes. A China é um caso importante nesse sentido não apenas por conta da dimensão e da força do seu aparato estatal, mas também porque tem feito um movimento robusto de construção de um sistema de proteção social nos anos recentes. A transição do maoísmo para um regime que se diz "socialista de mercado" (ou um "capitalismo de Estado", segundo várias interpretações) representou, de início, o desmonte de praticamente toda e qualquer proteção social. Desde a virada do século, entretanto, tem havido um esforço sistemático por parte do Estado chinês de reconstrução de algum tipo de proteção social - e do qual sabemos pouco no Brasil tanto do ponto de vista das suas características quanto dos seus resultados preliminares.

Em resumo, sabe-se que apesar do resultado estrondoso do ponto de vista de taxas de crescimento econômico, as primeiras décadas das reformas na China vieram acompanhadas de um desmonte do sistema de políticas de bem-estar que vigorou ao longo do período maoísta (1949-1976). Entre os anos 1980 e 1990, os chineses enfrentaram não apenas o aumento da desigualdade de renda, com o índice de Gini passando de 0,30 no começo da década de 1980 para mais de 0,45 no começo da década de 2000 (Medeiros e Nogueira, 2011), como também se depararam com uma violenta redução dos seus programas de proteção social na saúde e educação. Isso levou à piora em indicadores fundamentais de bem-estar (inclusive com epidemias alargadas, como no caso da Síndrome Respiratória Aguda Grave - SARS) e a numerosos casos de famílias que foram à falência por gastos com saúde e serviços de educação, o que aumentou a insatisfação popular medida pelos chamados "incidentes de massa" (manifestações populares), cujos casos saltaram de 10 mil para 87 mil entre 1994 e 2005 segundo dados oficiais.

Em resposta a esse contexto cada vez mais tensionado, o atual sistema de proteção social começou a ser reestruturado a partir do final da década de 1990 e ao longo da década de 2000. Tal processo resultou na implementação dos três seguros sociais de saúde vigentes na China de hoje: o Urban Employee Basic Medical Insurance (UEBMI), introduzido em 1998 para cobrir os trabalhadores formais urbanos, o New Rural Cooperative Medical Scheme (NRCMS), iniciado em 2003 para atender os residentes rurais, e o Urban Resident Basic Medical Insurance (URBMI), introduzido em 2007 de forma a cobrir os residentes com registro de moradia (hukou) urbano não atendidos pelo UEBMI. No caso do sistema educacional, a administração de Hu Jintao e Wen Jiabao assumiu, em 2004, o compromisso de universalizar o acesso à educação compulsória (nove anos iniciais). Desde então foram abolidas oficialmente as cobranças de matrículas, mensalidades e taxas nas escolas públicas na fase da educação básica compulsória e implementadas políticas de livros didáticos gratuitos e de subsídios aos alunos de baixa renda. Contudo, a literatura é abundante quanto às formas de pagamento institucionalizadas em outros níveis (sobretudo na pré-escola, ensino médio e universidade) e à desigualdade no acesso ao ensino de qualidade.

Este artigo oferece uma caracterização do sistema de proteção social na China com foco nos sistemas públicos de saúde e educação, descrevendo detalhadamente as reformas, os 
programas implementados, cobertura ${ }^{1}$, generosidade ${ }^{2}$, os resultados alcançados e os principais problemas entre o início da década de 1980 até 2015 (últimos dados disponíveis). Reformas igualmente amplas têm sido feitas também na previdência, renda mínima e assistência, além de intervenções diretas no mercado de trabalho (por exemplo, via regulação do salário mínimo). Neste artigo, nós oferecemos os resultados dos levantamentos nas áreas da saúde e educação e os utilizamos como proxy do Estado de bem-estar social (EBES) que se desenha no caso chinês, além de realizarmos uma comparação qualitativa e livre com as tipologias de regimes de bemestar consolidadas na literatura e desenvolvidas tanto para países centrais quanto para países do leste asiático.

Além dessa introdução, este artigo divide-se em mais quatro seções. Na seguinte, são apresentadas considerações gerais sobre a origem do EBES no mundo, sua relação com o processo de desenvolvimento econômico, as principais tipologias e uma breve revisão da literatura sobre o caso asiático. Em seguida, detalharemos o sistema chinês de proteção social na saúde e na educação, incluindo suas principais reformas, resultados alcançados, contradições e desafios presentes. A seção subsequente busca construir comparações dos sistemas de saúde e educação chineses com as tipologias consolidadas na literatura sobre Estado de bem-estar, ressaltando as similaridades e diferenças do caso da China com outros regimes de proteção social. Por fim, sumarizaremos os principais resultados encontrados.

\section{0 estado de bem-estar social: características gerais, regimes ocidentais e as experiências asiáticas}

O Estado de bem-estar social carrega alguns dos germes imprescindíveis para uma vida salutar em sociedade. Esse conjunto articulado de políticas e instituições expressa "o reconhecimento de algum tipo de responsabilidade pública sobre o bem-estar 'social', isto é, de todos" (Kerstenetzky, 2011, p. 88). A responsabilização pública implica em proteção contra os riscos ordinários ao bem-estar que impeçam a realização de rendimentos (doença, envelhecimento, acidentes de trabalho, desemprego) e no estabelecimento de um orçamento público social que promova o bem-estar, além da geração de um tipo mínimo de cidadania política, concebida como precondição para o acesso aos benefícios sociais.

Essa responsabilização pública pelo bem-estar teve causas históricas variadas e nem sempre altruístas, e todas compondo, em maior ou menor grau, com objetivos de controle social, com a pressão da classe trabalhadora, e com políticas de estímulo ao desenvolvimento econômico ${ }^{3}$. Por exemplo, as bases do EBES moderno remontam ao final do século XIX com a Alemanha de Bismarck, quando as políticas de bem-estar eram vistas como um instrumento

\footnotetext{
(1) Percentual da população atendida.

(2) Nível de benefícios oferecidos.

(3) Um grupo de autores chama atenção para a "multifuncionalidade da política social", destacando as consequências benéficas desse conjunto de ações na sociedade, como, por exemplo, via estímulo ao crescimento econômico, estabilização social, legitimação política, para além dos efeitos da política social em si mesma (Kerstenetzky, 2011, p. 134-135; Kwon; Mkandawire; Palme, 2009, S3-S4).
} 
para tentar brecar o avanço da oposição e da democracia e com evidentes objetivos de controle social (Esping-Andersen, 1990). Conforme a industrialização e a urbanização expandiram-se e os conflitos entre capital e trabalho avolumaram-se, os partidos ou movimentos de centroesquerda e extrema esquerda passaram a representar um desafio concreto aos interesses consolidados. Isso fez com que mais Estados oferecessem bens e serviços públicos, lançando seus programas de educação pública limitada, saúde pública e regulação das condições de trabalho (Pierson, 1991).

A partir de meados do século XX, as políticas sociais passaram a ser percebidas como um incentivo ao crescimento econômico ao fornecer estímulos à inovação a partir da segurança econômica e dos investimentos em educação. Além dos impactos sociais - como redução de pobreza e desigualdade e promoção do acesso à educação e saúde e da justiça social -, as políticas sociais passaram a ser defendidas pelos seus efeitos econômicos: ao reduzir os riscos sociais, os ciclos de consumo são suavizados, mitigando as incertezas e promovendo a estabilização econômica. Por conseguinte, os custos de investir em determinado local são reduzidos e há impulsos à produtividade (Kerstenetzky, 2011b; Kerstenetzky e Kerstenetzky, 2015). Nessa perspectiva, a existência de um sistema de proteção social seria instrumental para o próprio crescimento econômico.

\subsection{Regimes de bem-estar social no ocidente e na Ásia}

Há vários tipos de EBES pelo mundo. O trabalho seminal de Esping-Andersen (1990) popularizou-se por ser uma primeira tentativa de sistematizar essas diferenças por meio de regimes (ou tipologias) amplos. Apesar de amplamente criticado e das inúmeras tentativas de reclassificações (ver Bambra, 2007; Arts; Gelissen, 2002; Leibfried, 1992; Ferrera, 1996; Bonoli, 1997; Castles, 1998), Esping-Andersen continua sendo a referência inicial.

Os critérios utilizados para sua primeira categorização foram (i) grau de desmercantilização promovida, ou em que medida o sistema de proteção social é capaz de reduzir a dependência dos cidadãos em relação ao mercado para garantia de bem-estar; (ii) tipo de estratificação social resultante da ação do EBES; e, (iii) o relacionamento entre Estado, mercado e família no tocante à provisão de bem-estar. A partir da combinação desses critérios, Esping-Andersen sugeriu a existência de três tipos distintos de EBES:

i) Welfare State liberal (exemplo: Estados Unidos): o Estado estimula que o mercado seja o locus primário de obtenção de bem-estar. A assistência é residual, com poucas transferências ou benefícios universais. Oferece baixo grau de desmercantilização e edifica uma ordem de estratificação dual: aqueles que recorrem ao mercado obtêm bem-estar diferenciado ao dos mais pobres, receptores dos benefícios estatais e entre os quais há igualdade. Usualmente mantém o estigma de ser receptor dos benefícios do Estado.

ii) Welfare State conservador ou corporativista (exemplo: Áustria, Alemanha e Itália): há ênfase na diferenciação de categorias sociais, ou seja, os direitos sociais estão ligados ao status profissional do indivíduo - o acesso e o valor do benefício recebido 
dependem da posição ocupada no mercado de trabalho. Este modelo também mantém a dependência do indivíduo com relação à família, uma vez que o Estado age apenas quando a família não é capaz de atender às demandas. Por outro lado, este regime torna o indivíduo menos dependente do mercado do que no caso do modelo liberal.

iii) Welfare State socialdemocrata (exemplo: países nórdicos): baseia-se no princípio de solidariedade e universalização dos riscos. As políticas sociais são universalistas, inclusivas e oferecem benefícios elevados, abrangendo diversos aspectos da vida; os benefícios são vistos como direito social e há forte comprometimento com o princípio de igualdade. Busca programas que garantam a desmercantilização e incorpora todas as camadas sociais, excluindo o mercado desta esfera, além de eliminar a dependência do indivíduo com relação à família.

Dentre as várias questões levantadas pelos críticos da tipologia de Esping-Andersen, está o fato de que ele se adequa pouco à trajetória dos países do leste asiático (Japão, Coréia do Sul, Taiwan, Hong Kong e Cingapura). Uma parte relevante da literatura asiática qualifica o EBES desta região como "bem-estar desenvolvimentista" ou "produtivista". Nele, o Estado atuaria na própria estrutura econômica, evitando dispersões salariais, garantindo a distribuição equitativa da terra e promovendo políticas de estímulo ao pleno emprego. Ao invés de derivarem sua legitimidade dos ideais de justiça social e equidade, esses EBES asiáticos estariam ancorados em objetivos produtivos, com as políticas sociais sendo apresentadas como instrumento de crescimento econômico (Kwon et al., 2009; Choi, 2012; Chan e Lin, 2013).

Isso implicaria em uma mistura particular: ao mesmo tempo em que o Estado teria uma atuação na política social aparentemente residual, deixando um espaço amplo para atuação da família na provisão de bem-estar, ele teria um papel extremamente forte e interventor tanto como planejador econômico quanto em várias esferas da produção ditas como próprias da ação direta de agentes do mercado.

Em sua primeira fase (do pós-guerra até a década de 1990), o Estado de bem-estar desenvolvimentista asiático tendeu a ser seletivo em sua cobertura, favorecendo especialmente os atores importantes para o crescimento, notadamente o trabalhador urbano industrial. Muitos programas de saúde, previdência e auxílio-doença estavam centrados nas grandes empresas, sendo elas próprias financiadoras desses sistemas, reservando ao Estado o papel de regulador, mas não de provedor principal. Nesse sistema, a maior parte da população mais vulnerável permaneceu descoberta (Kwon et al., 2009).

As principais caraterísticas da primeira fase (1980-1990) dos EBES dos países do leste asiático (até as mudanças causadas pela crise financeira asiática) são: 1. limitação dos gastos sociais públicos; 2. forte papel exercido pelo Estado como regulador, sendo uma parte da provisão essencialmente das empresas; 3. provisão de bem-estar oferecida a partir de programas segmentados, o que resultou em programas generosos para trabalhadores industriais e funcionários do Estado, e programas precários para trabalhadores autônomos e rurais; 4. papel central desempenhado pelas famílias, resultado do baixo montante destinado pelo governo à 
provisão de serviços sociais. Tais características foram acompanhadas por um Estado fortemente atuante na própria estrutura do sistema econômico, evitando dispersões salariais e regulando de perto várias instituições, inclusive o mercado de trabalho. Isso explica o bom perfil distributivo da maior parte desses países (baixa desigualdade) apesar de um EBES "pequeno" (Miyamoto, 2003).

Esse sistema, porém, sofreu modificações importantes ao longo dos anos 1990, principalmente a partir da crise financeira do leste asiático. Somado às mudanças demográficas e ao aumento da desigualdade verificado nesta mesma década, ficou claro que o modelo não protegia a população dos riscos econômicos, sobretudo quando a economia ia mal. Assim, embora o modelo produtivista não tenha sido abandonado de todo, a política social como instrumento de estabilidade social passou a ser uma preocupação do Estado, fazendo com que os gastos sociais aumentassem sua parcela no PIB e ganhassem um papel redistributivo mais próprio da Europa (Chan; Lin, 2013). Isso significou expressivo incremento no gasto social japonês, que passou de $11 \%$ do PIB para $23 \%$ do PIB entre 1990 e o final da década de 2000, alcançando a média dos demais países da OCDE. O aumento no gasto social veio acompanhado, entretanto, do crescimento dos trabalhadores sem contratos fixos, o que elevou a incerteza e a insegurança no mercado de trabalho (Lee, 2015).

Na China, a busca por uma sociedade menos desigual passou a ser a tônica do Partido Comunista desde o final da década de 1990, o que foi resumido no slogan do presidente anterior, Hu Jintao, de construção de uma "sociedade harmoniosa". Atualmente, a proposta do $13^{\circ}$ Plano Quinquenal (2016-2020), sob o governo de Xi Jinping, tem como um de seus princípios a busca pelo desenvolvimento inclusivo, com expansão dos serviços sociais e maior igualdade entre áreas urbanas e rurais. Foi colocado como um dos objetivos principais a melhoria dos níveis de subsistência e qualidade de vida, a ser alcançado pelo aperfeiçoamento e maior equidade dos sistemas de serviços públicos, incluindo os de saúde, educação e seguridade social. Há a meta de retirar todos os residentes rurais da pobreza, modernizar a educação básica pública e garantir o acesso ao sistema básico de saúde para todos os cidadãos.

A próxima seção descreve as reformas já realizadas no sistema de seguros sociais de saúde e de educação da China a partir da década de 1980 e suas principais características.

\section{0 sistema de proteção social na saúde e na educação na China entre 1980-2015}

Se não há dúvidas de que a performance econômica da China foi espetacular nas últimas décadas, sobretudo do ponto de medidas simples como o PIB per capita, seus resultados em termos de bem-estar foram menos impressionantes. Ao mesmo tempo em que a pobreza (medida do ponto de vista monetário) foi reduzida expressivamente, famílias foram levadas à falência nos anos 1990 e 2000 em função de gastos exorbitantes com saúde, e epidemias graves, como a SARS, foram causadas em parte pela dificuldade de acesso a tratamentos médicos pela população pobre. Isso tudo acompanhado do tensionamento social em função do acentuado crescimento da desigualdade de renda e de riqueza. 
Tal situação pode ser atribuída ao limbo no sistema de bem-estar para o qual uma parcela significativa da população foi sendo empurrada durante duas décadas. As reformas implementadas a partir de 1978 implicaram no gradual desmantelamento das comunas rurais e na reestruturação das empresas estatais (SOEs), o que levou ao aniquilamento das bases do sistema de bem-estar do período maoísta (1949-1976). Foi apenas a partir do início da década de 2000 que o sistema de seguridade atual começou a ser construído (Chen; Turner, 2015).

Melhorias têm sido obtidas desde então, embora a descentralização fiscal com fraca rede de redistribuição entre províncias ricas e pobres implique em uma enorme disparidade regional. O maior avanço obtido até agora veio na educação básica. Os primeiros nove anos de educação tornaram-se efetivamente universais e gratuitos desde 2007, sem as cobranças das taxas que haviam se disseminado a partir dos anos 1990 e haviam mantido crianças pobres longe das escolas. Similarmente, a assistência social ganhou fôlego com o Minimal Living Security System (Dibao), que atendia 52 milhões de cidadãos chineses rurais no final de 2014 (Li; Walker, 2016). Programas de previdência pública também se expandiram, embora de forma fragmentada, com regras e benefícios distintos para trabalhadores urbanos, residentes rurais, moradores urbanos sem emprego formal, membros do partido, militares e migrantes (Chen; Turner, 2015).

A divisão rural-urbana do sistema de bem-estar do período maoísta persistiu após seu fim, sendo a população urbana consistentemente mais favorecida. O sistema de registro de residência (hukou), implantado para controlar a migração interna é um dos causadores de tal segmentação, pois atrela os programas de benefícios sociais aos quais o indivíduo é elegível àqueles de seu local de residência oficial. Conforme Chen e Turner (2015) mostram, a política social é altamente descentralizada na China tanto do ponto de vista administrativo quanto fiscal, e a maior parte dos programas é incumbência dos governos municipais. Consequentemente, além do gap rural-urbano, há desigualdades inter-regionais no interior de cada programa decorrentes da diferença no nível de desenvolvimento econômico entre as regiões.

Este movimento de retração da provisão pública entre 1980 e 1990 e expansão a partir da década de 2000 é observado também no sistema de proteção social de saúde, assim como a fragmentação e a disparidade. A seguir serão descritas as reformas implementadas neste setor, examinando os principais seguros sociais, resultados alcançados e os problemas e desequilíbrios preponderantes.

\subsection{Do desmonte do sistema maoísta à criação dos seguros sociais de saúde}

Durante o período maoísta, a população chinesa era atendida pelo Rural Cooperative Medical Scheme (RCMS) nas áreas rurais e através do Government Employee Insurance Scheme (GIS) ou Labor Insurance Scheme (LIS) nas zonas urbanas. A política de saúde do governo obtinha bons resultados considerando-se o baixo nível de renda per capita, o que rendeu elogios por parte da Organização Mundial de Saúde e inclusive do Banco Mundial. 
As reformas econômicas introduzidas no final da década de 1970 levaram ao desmonte dos programas preexistentes. A substituição das comunas rurais pelo sistema de responsabilidade familiar no campo significou a desmobilização da base de arrecadação do RCMS, que foi sendo extinto ao longo da década de 1980. Nas áreas urbanas, as reestruturações das empresas estatais (SOEs) permitiram que dezena de milhões de trabalhadores fossem dispensados (Chan, Ngok e Phillips, 2008). Com o fim do financiamento governamental ao LIS e o incentivo à maior competição na economia, um número crescente de SOEs deixou de pagar as despesas médicas de seus empregados (Liu, 2002). Em 1998, em meio ao desmonte, a população atendida por algum seguro de saúde chegou a míseros 5\% na zona rural e 38\% nas áreas urbanas (Yu, 2015).

Essas modificações fizeram com que os gastos individuais saltassem de $21 \%$ para $60 \%$ dos gastos totais com saúde entre 1980 e 2001. Ao mesmo tempo, a saúde da população se deteriorou, havendo o ressurgimento de doenças como a esquistossomose e a malária em algumas províncias. Diversos problemas sociais foram associados a esse quadro, como o aumento da pobreza causada por grandes despesas médicas e a população sem acesso aos cuidados necessários, o que alimentou a insatisfação social. $\mathrm{O}$ descuido com a saúde pública ficou especialmente evidente com a epidemia de SARS em 2003, que marcou o ponto de inflexão da política governamental.

Dado este cenário, o governo chinês contava com dois principais incentivos para realização de novas reformas, desta vez objetivando expandir o sistema social de saúde: (i) a ideologia oficial do Partido Comunista Chinês (PCC) continuava sendo o socialismo, de forma que havia a necessidade de garantir algum bem-estar social à população de maneira ampla, sob o risco de o governo perder legitimidade; (ii) a mudança na estratégia de desenvolvimento da China, que passou a incluir a construção de uma "sociedade harmoniosa" e a depender do consumo e do poder de compra interno como instrumento de alavancagem do crescimento do PIB. O sistema de seguro social de saúde se enquadra na construção de tal sociedade, caracterizada por alguma segurança social (Yu, 2015).

Nesse contexto foi criado o New Rural Cooperative Medical Scheme (NRCMS) em 2003, cuja cobertura alcançou mais de 99\% da população rural em 2013 (China Statistical Yearbook 2015), sendo esta rápida expansão impulsionada pelo financiamento governamental, responsável por cerca de $80 \%$ do seu financiamento total. O NRCMS é um programa de responsabilidade do Ministério da Saúde e com financiamento realizado a partir de contribuições individuais, do governo local e do governo central, variando a proporção de acordo com as condições socioeconômicas. Beneficiários com mais dificuldades financeiras podem ainda ter sua parte da contribuição coberta pelo Medical Financial Assistance Program.

Antes disso, em 1998, já havia sido criado o Urban Employee Medical Insurance (UEBMI), programa de seguro social de saúde individual e compulsório que atende os empregados urbanos formais - portanto a parcela mais favorecida da população, considerando os três principais programas existentes. O financiamento é feito em conjunto pelos 
empregadores e empregados, estando os aposentados isentos. Embora o UEBMI tenha sido eficaz para expandir a população coberta, ele não resolveu satisfatoriamente os problemas de saúde das regiões urbanas, uma vez que exclui todos que não contam com emprego formal, como idosos, estudantes, pessoas com deficiência e a enorme massa de trabalhadores informais. Para suprir esta lacuna, foi criado em 2007 o Urban Resident Basic Medical Insurance (URBMI).

Com a nova política, a parcela dos gastos individuais nos gastos totais com saúde caiu de $60 \%$ em 2001 para $32 \%$ em 2014, representando um avanço significativo, embora permaneça em um patamar alto (Gráfico 1). Na configuração atual, o governo central é responsável pelo estabelecimento da legislação nacional e diretrizes gerais da política de saúde, mas é incumbência do governo local prover os cuidados de saúde de acordo com as condições e possibilidades da região. Com a expansão dos três programas - NRCMS, UEBMI e URBMI - a China alcançou a universalização da população coberta por algum tipo de seguro saúde em 2011.

Gráfico 1

Parcela dos gastos individuais com saúde (\% dos gastos totais com saúde)

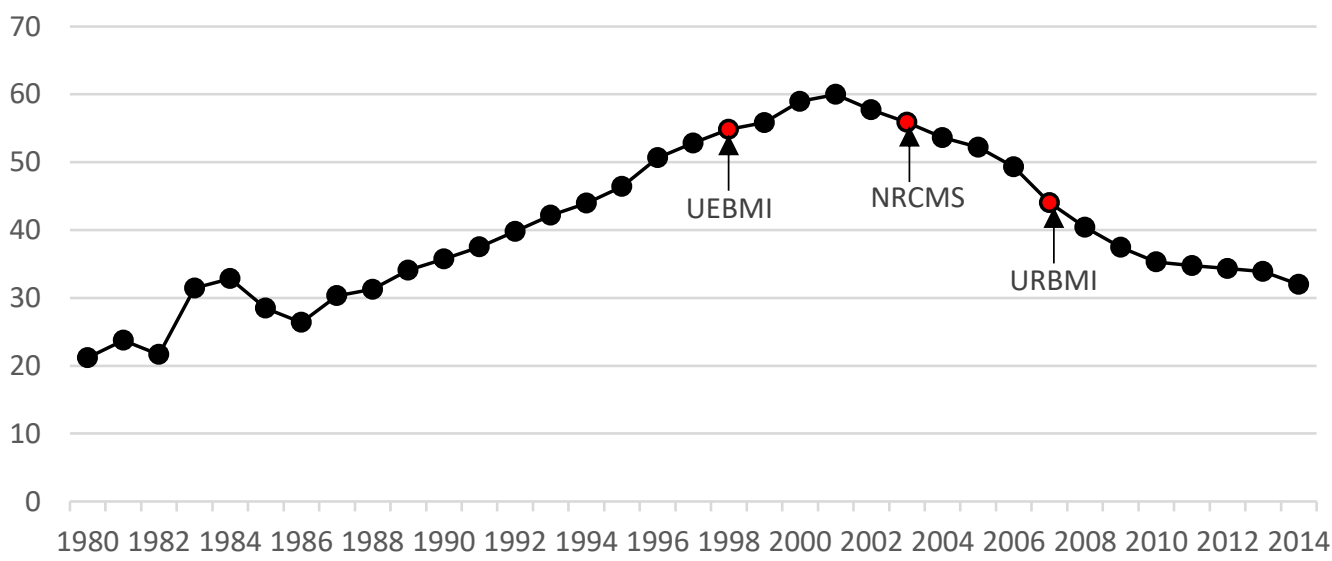

Fonte: Elaboração dos autores (China Statistical Yearbook, 2015).

\subsection{Resultados alcançados na saúde e seus principais limites e desequilíbrios}

A expansão da capacidade do sistema e o aumento dos serviços públicos oferecidos gratuitamente à população, como os programas de imunização, tiveram impactos positivos nos indicadores de saúde. A expectativa de vida ao nascer da China passou de 69,3 anos para 75,78 entre 1990 e 2014; relacionada a este avanço está a queda da mortalidade infantil até os cinco anos de idade (taxa a cada 1000 nascimentos), que despencou de 53,8 para 11,40 neste mesmo período. Embora seja necessário um período mais longo para poder medir o impacto da expansão dos seguros sociais de saúde, a universalização de sua cobertura é relevante para os avanços apresentados, pois democratiza o acesso aos cuidados inclusos (UNDP, 2016). 
Atualmente, os indicadores de saúde chineses já apresentam resultados melhores do que os dos países dos BRICS, excetuando a Rússia, e superando ainda a média do leste asiático e do mundo (Tabela 1). Tudo isso com um gasto per capita relativamente baixo (permanece, contudo, um gap significativo com os números das regiões mais desenvolvidas). Uma provável explicação para os bons resultados chineses com gastos relativamente baixos reside na estrutura da oferta, em que o papel estatal é predominante. O cuidado primário de saúde é fornecido através das chamadas "clínicas de vila" (village clinic), das quais apenas 29,39\% possuíam administração privada ou mista em 2014, sendo os demais 70\% estatais (China Statistical Yearbook, 2015). Mesmo com o incentivo estatal para a construção de hospitais privados oferecidos a partir da década de 2000, os hospitais também são na sua maioria públicos (55\%), principalmente nas áreas rurais. A forte atuação estatal significa que as taxas cobradas pelos cuidados primários podem ser controladas, sendo diretamente reguladas pelo governo local, além de haver subsídios governamentais para algumas drogas e serviços (The Common Wealth Fund, 2016).

Tabela 1

Indicadores de saúde e gastos com saúde de distintas regiões do mundo em 2014

\begin{tabular}{l|c|c|c|c|c}
\hline & $\begin{array}{c}\text { Expectativa } \\
\text { de vida ao } \\
\text { nascer (anos) }\end{array}$ & $\begin{array}{c}\text { Taxa de } \\
\text { mortalidade em } \\
\text { menores de 5 } \\
\text { anos (1.000 } \\
\text { nascimentos) }\end{array}$ & $\begin{array}{c}\text { Taxa de } \\
\text { mortalidade } \\
\text { materna } \\
(100.000 \\
\text { nascimentos) }\end{array}$ & $\begin{array}{c}\text { Gasto per } \\
\text { capita com } \\
\text { saúde (PPP, a } \\
\text { preços } \\
\text { internacionais } \\
\text { constantes de } \\
2011)\end{array}$ & $\begin{array}{c}\text { Gasto público } \\
\text { com saúde (\% } \\
\text { do PIB) }\end{array}$ \\
\hline Brasil & 74,40 & 16,20 & 65 & $1.318,17$ & 3,83 \\
\hline Rússia & 70,37 & 9,90 & 29 & $1.835,71$ & 3,69 \\
\hline Índia & 68,01 & 49,80 & 215 & 267,41 & 1,41 \\
\hline China & 75,78 & 11,40 & 35 & 730,52 & 3,10 \\
\hline África do Sul & 57,18 & 41,40 & 154 & $1.148,37$ & 4,24 \\
\hline Leste asiático e Pacífico & 74,93 & 17,85 & 74 & 903,11 & 4,56 \\
\hline Japão & 83,59 & 2,80 & 6 & $3.726,68$ & 8,55 \\
\hline Coreia do Sul & 82,16 & 3,60 & 12 & $2.530,57$ & 3,99 \\
\hline UE & 80,67 & 4,56 & 8 & $3.524,19$ & 7,82 \\
\hline EUA & 78,94 & 6,70 & 14 & $9.402,54$ & 8,28 \\
\hline Mundo & 71,45 & 43,90 & 246 & $1.275,72$ & 5,99 \\
\hline Fonte: Elabocan & & & & \\
\hline
\end{tabular}

Fonte: Elaboração dos autores (Banco Mundial).

Apesar dos avanços e da universalidade dos programas sociais de saúde, a população chinesa não desfruta do acesso aos mesmos benefícios, pois eles variam de acordo com o programa no qual a pessoa está inscrita - o que depende principalmente do seu hukou, de sua ocupação profissional e do nível de desenvolvimento econômico da região (ver Quadro 1 para uma comparação sistematizada). 
O sistema de seguro social de saúde reproduz desde sua origem a desigualdade ruralurbana. Isso fica evidente, por exemplo, quando se observa o gap no gasto per capita com saúde, embora o mesmo esteja ficando gradativamente menor - em 1990, o gasto per capita com saúde nas zonas rurais equivalia a apenas $25 \%$ do das áreas urbanas, tendo passado para 39\% em 2013. Essa diferença pode ser explicada principalmente a partir das disparidades da generosidade dos programas que atendem cada grupo e pelas desigualdades socioeconômicas verificadas entre regiões rurais e urbanas.

Os benefícios recebidos pelo segurado são determinados por sua posição social. O programa baseado na ocupação profissional (UEBMI) oferece os maiores benefícios, embora atenda parcelas menores da população. Os programas com critério residencial (URBMI e NRCMS), por outro lado, cobrem mais pessoas, mas concedem graus mais baixos de benefício, abarcando menos serviços e drogas e propiciando menor valor de reembolso. A chance de ser inscrito nos programas com benefícios mais amplos aumenta significativamente caso o trabalhador seja do setor público e/ou seu empregador seja de maior porte. O status socioeconômico, entendido como nível de educação e de renda, e a detenção de hukou urbano também têm correlação positiva com a inscrição no UEBMI (Huang, 2014, 2015).

Assim, Huang fala do paradoxo produzido pelas reformas no sistema de seguro social de saúde na China: a criação do UEBMI, URBMI e NRCMS aumentou significativamente a população coberta, mas as desigualdades sociais foram reproduzidas nesse modelo, aprofundando e solidificando as separações preexistentes da sociedade chinesa. Não apenas o sistema mantém a desigualdade entre as populações rurais e urbanas, como ainda realiza separação dentro das regiões urbanas de acordo com a posição do indivíduo no mercado de trabalho e com o setor (privado ou público) em que está empregado. Para este autor, as desigualdades existentes entre grupos sociais no sistema de seguro social de saúde na China não são acidentais. Embora o governo central tenha interesse em não permitir um gap muito grande entre classes sociais, o que alimentaria conflitos sociais e poderia reduzir a legitimidade do regime, conceder tratamento distinto de acordo com a classe social permite simultaneamente que sejam mantidos privilégios reservados às suas bases de apoio e que a mobilização horizontal do restante da sociedade seja dificultada, uma vez que cada classe terá preferências e interesses diferentes dados os respectivos tratamentos. Neste sentido, o sistema de seguro social de saúde funciona também como um instrumento de controle social, impedindo o fortalecimento de ameaças ao governo através da consolidação da estratificação da sociedade.

Ao analisar os programas individualmente, a generosidade varia de acordo com a província. Para Chan, Ngok e Phillips (2008), as desigualdades regionais persistem essencialmente por conta da descentralização do governo central, o que faz com que os governos das regiões mais pobres, que não contam com recursos financeiros significativos, sejam responsáveis pela maior parte do financiamento do seguro social de saúde, reproduzindo a desigualdade de desenvolvimento econômico. 
Quadro 1

Resumo dos principais seguros sociais de saúde da China, 2011-2013

\begin{tabular}{|c|c|c|c|}
\hline & UEBMI & URBMI & NRCMS \\
\hline Ano de início & 1998 & 2007 & 2003 \\
\hline População alvo & $\begin{array}{c}\text { Trabalhadores formais } \\
\text { urbanos }\end{array}$ & $\begin{array}{c}\text { Residentes urbanos não } \\
\text { inclusos no UEBMI }\end{array}$ & Residentes rurais \\
\hline $\begin{array}{c}\text { Número de pessoas cobertas } \\
\text { em } 2011 \text { como } \% \text { da } \\
\text { população chinesa ( } 1,3 \text { bi) }\end{array}$ & 19 & 16 & 62 \\
\hline Fonte de Financiamento & $\begin{array}{c}\text { Contributivo ( } 8 \% \text { da } \\
\text { folha salarial anual, } 6 \% \\
\text { dos empregadores e } 2 \% \\
\text { dos empregados) }\end{array}$ & $\begin{array}{l}\text { Subsídios } \\
\text { governamentais }(70 \%) \text { e } \\
\text { prêmio individual }(30 \%)\end{array}$ & $\begin{array}{c}\text { Subsídios } \\
\text { governamentais }(80 \%) \mathrm{e} \\
\text { prêmio individual } \\
(20 \%)\end{array}$ \\
\hline Pacote de Serviços & Compreensivo & Limitado & Limitado \\
\hline $\begin{array}{l}\text { Taxa do reembolso para } \\
\text { paciente internado }(\%)\end{array}$ & 68 & 48 & 44 \\
\hline Teto de reembolso anual & $\begin{array}{l}\text { Seis vezes o salário } \\
\text { médio do trabalhador } \\
\text { urbano local }\end{array}$ & $\begin{array}{c}\text { Seis vezes o rendimento } \\
\text { disponível do residente } \\
\text { local }\end{array}$ & $\begin{array}{l}\text { Seis vezes a renda dos } \\
\text { agricultores locais }\end{array}$ \\
\hline
\end{tabular}

Fonte: Adaptado de Meng et al. (2015) e Yu (2015).

Outro problema associado ao sistema de saúde atual refere-se aos trabalhadores migrantes, que ocupam uma das posições mais vulneráveis na sociedade chinesa. As reformas econômicas foram acompanhadas por grande influxo de trabalhadores de áreas rurais para zonas urbanas em busca de melhores oportunidades, o que garantiu mão de obra para atividades industriais da costa. A integração social, porém, não acompanhou tal movimento. A manutenção do hukou rural faz com que os migrantes continuem inscritos no programa de sua região de origem, o que representa um obstáculo financeiro para tais pessoas, tendo em vista a menor generosidade do NRCMS quando comparado aos seguros sociais de saúde urbanos. Outra questão é a exigência de que o migrante retorne à sua região de origem para obter o reembolso de suas despesas médicas, elevando o custo de transação incorrido (Yu, 2015). Assim, os migrantes carecem de acesso a cuidados preventivos e de imunização, têm menos informações e não vão regularmente a médicos, o que é agravado pela maior vulnerabilidade dos trabalhadores migrantes a riscos de saúde, dado que suas condições de trabalho e de moradia tendem a ser mais precárias. Contudo, a tendência futura é de inclusão dos migrantes nos programas das localidades onde vivem, o que já ocorre em Shenzhen, por exemplo. Há regiões que permitem que os migrantes participem do URBMI, enquanto outras possuem seguros específicos para essa população (Zhu et al., 2008, Li et al., 2014; Müller, 2016).

Por fim, os problemas vão além daqueles presentes nos seguros sociais de saúde, levando à elevada insatisfação da população com o sistema de saúde vigente e à necessidade de continuidade das reformas. Uma questão relevante é a lotação dos grandes hospitais 
públicos, resultado da insuficiência de clínicas voltadas ao fornecimento de cuidados primários e da falta de confiança dos usuários com relação a outras instituições (Kurtzig; Wang, 2017).

O sistema tende a ser mais pressionado com o envelhecimento populacional e o setor privado tem emergido para suprir a demanda por serviços que hoje não são satisfatoriamente atendidos. O mercado de seguros de saúde privados cresceu $60 \%$ na virada de 2014 para 2015 , impulsionado pelo estímulo governamental, que reduziu restrições regulatórias no setor e passou a oferecer incentivos fiscais aos consumidores que adquiram serviço ${ }^{4}$. Todavia, os seguros privados representam, por enquanto, uma fatia diminuta do total de seguros de saúde no país $(E Y, 2016)$. Por outro lado, hospitais privados já representam quase metade dos hospitais do país (45\%), segundo The Common Wealth Fund (2016).

Em agosto de 2016, o governo chinês publicou "Healthy China 2030", que estabelece as diretrizes da continuação das reformas no setor de saúde. Resumidamente, busca-se priorizar cuidados preventivos e uma abordagem mais compreensiva da saúde, abarcando não apenas os aspectos médicos, mas também ambientais e comportamentais, envolvendo os Ministérios da Saúde, Esportes, Meio Ambiente, Agricultura e Educação (Liu, 2017). O governo chinês também tem falado na possibilidade de unificar os três seguros sociais de saúde até 2020, já havendo regiões, como Tianjin e Qinghai, que iniciaram a fusão em 2014 do NRCMS e do URBMI. Há diversas dificuldades, contudo, para a concretização nacional de tal projeto, que não possui ainda nem suas diretrizes gerais estabelecidas pelo governo central (Meng et al., 2015).

\subsection{Reformas no sistema nacional de educação: descentralização controlada e mercantilização entre 1980 e meados dos anos 2000}

Não foi apenas o sistema de saúde que passou por importantes transformações estruturais. No contexto das reformas pelas quais passa a China, o Partido Comunista Chinês abriu espaço para um processo de descentralização controlada, passando a responsabilidade da provisão de serviços básicos, como educação, para os níveis inferiores de governo. Nesse período, iniciado em 1978, se dão várias reformas administrativas, econômicas e tributárias que alteram a capacidade de arrecadação e dão mais independência para os governos locais.

Em meados da década de 1980, a China assistiu à publicação de uma série de documentos que tinham como objetivo redesenhar a estrutura administrativa da educação chinesa para responder aos desafios das reformas econômicas que o país atravessava. Os governos locais se viram responsáveis por gerenciar uma série de serviços, inclusive educação, sem ter base tributária ou mesmo know-how para tal. Em 1984, o governo central admitiu a possibilidade de financiamento "complementar" para a educação compulsória rural, e em 1986

(4) 2015 foi o ano em que o programa piloto de oferecimento de benefícios fiscais foi instituído em uma grande cidade de cada província e em Pequim, Xangai, Chongqing e Tianjin: quem adquire um plano de saúde privado pode deduzir até RMB 2.400 de suas contribuições anuais do imposto de renda (EY, 2016). 
a cobrança de taxas "complementares" ao financiamento público da educação já era generalizada (Ngok, 2007; Du; Sun, 2016).

A provisão da educação se deu de forma completamente diferente em províncias ricas e pobres. Alguns governos locais se viram em dificuldades financeiras devido ao acirramento do processo de competição econômica promovido pelo governo central e repassaram os custos dos serviços de educação para a população (Ngok, 2007; Chan; Ngok; Phillips, 2008; Postiglione, 2015). Dessa forma, as regiões privilegiadas pelas reformas de Deng Xiaoping obtiveram relativo sucesso em manter a provisão de serviços nos seus territórios, sobretudo no caso das províncias costeiras e dos centros urbanos (Gao, 2010; Du; Sun, 2016; Liu, 2016).

Nas áreas rurais e no interior do país, observou-se o que o governo chinês chamou de "pobreza da educação", onde imperavam a falta de recurso, escolas sucateadas com profissionais pouco qualificados e mal pagos, falta de equipamentos e estrutura, além de uma oferta muito aquém das necessidades locais (Ngok, 2007; Postiglione, 2015). Nos anos de 1990, o interior rural da China observou a difusão das private tutoring cum boarding agencies, escolas rurais de baixíssima qualidade e de administração privada (Wong et al., 2007).

Ainda na década de 1990, o governo chinês adotou outras políticas com impactos contraditórios sobre o acesso à educação. A primeira delas é a Lei de Educação de 1995, que estabelece uma indexação entre o crescimento econômico regional e os gastos em educação. Logicamente, o financiamento à educação desde então apresenta uma tendência crescente no país, no entanto, as disparidades no desempenho econômico das regiões são transmitidas institucionalmente para os investimentos no setor. A segunda política se deu via a reforma tributária que desonerou os trabalhadores rurais. Nesse caso, uma parcela significativa da população sentiu um alívio considerável em função do aumento na renda disponível. Entretanto, uma série de governos municipais que dependiam dessas taxas perdeu muito poder de financiamento, o que resultou numa piora da provisão de educação nessas áreas.

Por outro lado, a década de 1990 também assistiu à mais impressionante expansão do ensino superior da história. Segundo dados do China Statistical Yearbook, o número de estudantes mais que dobrou entre 1990 e 2000, passando pouco mais de dois milhões de alunos para mais cinco milhões e quinhentos mil. Ainda segundo as estatísticas chinesas, mais de $60 \%$ dos alunos que se formaram no ensino médio no ano de 2000 ingressaram no ensino superior, contra menos de 30\% na década de 1990 (China Statistical Yearbook, 2016). Essa expansão representa, segundo alguns autores, uma mudança fundamental no papel estratégico do ensino superior no desenvolvimento chinês, que passa a exercer um potencial formador de mão de obra qualificada para atender aos desafios criados com as transformações da sociedade chinesa (Ngok, 2007; Postiglione, 2016).

Nessa trajetória de avanços e retrocessos, os resultados do sistema de educação chinês no final dos anos de 1990 podem ser descritos a partir de alguns dados emblemáticos. Enquanto nove das 33 regiões chinesas alcançaram $100 \%$ de cobertura nos nove anos de educação compulsória, outras sete regiões permaneceram abaixo de 60\%. Pequim e Xangai 
universalizaram 12 anos de educação ao mesmo tempo em que $20 \%$ da população rural chinesa não frequentava a escola. Entre o litoral e o interior, as diferenças nas taxas de matrícula chegam a quase $20 \%$. Além disso, persistiram diferenças de gênero significativas que se refletem nas taxas de abandono, nas quais a meninas representavam $75 \%$ no ensino primário (Postiglione, 2015).

As diferenças no sistema educacional se traduziram em distintos graus de escolaridade no início do século XXI. Enquanto $44,1 \%$ da população com registro urbano havia concluído ou cursava o ensino médio em 2001, entre os residentes rurais, apenas 5,7\% atingiram o mesmo feito. A taxa de analfabetismo urbana no mesmo período era de $6,5 \%$, contra $19,2 \%$ no meio rural (Wong et al., 2007).

Em resumo, assim como no caso da saúde, a educação chinesa atravessou uma sucessão de crises e desequilíbrios durante as décadas de 1980 e 1990. A população observou o crescimento exorbitante dos gastos individuais com o setor consumirem parcelas proibitivas da sua renda e o governo chinês viu as disparidades regionais e o gap urbano-rural se alargarem. A insatisfação popular e o já mencionado crescimento dos incidentes de massa levaram o governo chinês a tentar corrigir alguns dos problemas criados ou intensificados no período das reformas. A expansão do ensino superior promovida já desde os anos 1990, a criação de programas focalizados de combate a casos extremos e a reversão no padrão de financiamento da educação nos anos 2000 apontam nesse sentido.

O governo central promoveu uma importante inflexão na direção da educação chinesa a partir de meados dos anos 2000. No período que ficou conhecido como "Sociedade Harmoniosa", o Partido-Estado intensificou a participação pública no padrão de financiamento da educação e derrubou barreiras no acesso à educação compulsória, sobretudo através da proibição de cobrança de matrículas e outras taxas dos estudantes.

\subsection{O sistema atual de educação: características e principais problemas}

A estrutura geral do sistema de educação no país é estatal e oficialmente descentralizada desde 1985 (Ngok, 2007). Os governos municipais são responsáveis pela educação primária e secundária, enquanto as províncias são responsabilizadas pelo ensino superior (Du e Sun, 2016). O governo central é o principal promotor de políticas, estratégias e planos que regem a educação em todo o país, além de fiscalizar, regulamentar e direcionar a educação privada. O financiamento da educação (80\% público em 2014), assim como a administração, vem em grande parte do orçamento dos governos locais (mais de $90 \%$ do financiamento público total em 2014) e ao governo central cabem algumas transferências e políticas focalizadas, como o "Mecanismo de Fundo de Garantia" e o programa "Duas Isenções e Um Subsídio" (Du e Sun, 2016; China Statistical Yearbook, 2016).

O sistema de educação chinês conta hoje com nove anos de educação compulsória, conforme estabelecidos pela lei homônima de 1986. Nem a pré-escola, nem o ensino médio são obrigatórios (ou mesmo gratuitos), o que se reflete nas taxas de matrícula dessas etapas. 
No âmbito da educação compulsória, uma barreira que o governo chinês tenta até hoje derrubar é o exame de entrada da primeira etapa do ensino secundário. Apesar de ter diversas legislações proibitivas desde a década de 80 , as escolas utilizam subterfúgios para contornar as legislações vigentes que obrigam à matrícula baseada na localidade. Outro desafio enfrentado pelo governo central é fazer valer a gratuidade garantida pela Lei da Educação Compulsória (OCDE, 2016). Em geral, quem encontra maior dificuldade em matricular seus filhos nas escolas gratuitamente, ou até simplesmente matricular, são os migrantes sem hukou urbano. Além de sobretaxas, muitas vezes a documentação exigida pelas escolas se torna proibitiva e muitos acabam recorrendo a escolas privadas de má qualidade (Wong et al., 2007; Gao, 2010).

$\mathrm{O}$ acesso à pré-escola continua sendo um grande desafio para o governo chinês. Durante a década de 90, a China reduziu a provisão pública do serviço, afetando diretamente a cobertura dessa etapa. Por sua vez, o setor privado cresceu desde então e em 2015 representava mais de $60 \%$ do número de escolas e professores, além de mais de $50 \%$ das matrículas (China Statistical Yearbook, 2016). A maior preocupação de Pequim é com a expansão do acesso, e o governo tem atuado tanto na expansão do financiamento público quanto na regulamentação do setor privado com o objetivo de universalizar o serviço até 2020 (Cui, 2017). Nesse contexto, a quantidade de pré-escolas quase dobrou entre 2005 e 2015 e a cobertura saltou de $60 \%$ em 2007 para mais de $80 \%$ em 2015, mas com forte atuação privada (China Statistical Yearbook, 2016; OCDE, 2016).

O ensino médio é, até hoje, o principal divisor de águas do sistema educacional do país. Em 2012, enquanto 80\% dos alunos formados no ensino secundário júnior em escolas urbanas se matricularam no ensino médio, no caso das escolas rurais, apenas $10 \%$ desses alunos tiveram o mesmo destino (Zhang, 2016). Os principais responsáveis pela criação de barreiras ao acesso nessa etapa são a política de "escolas chave" e o zhongkao. A política de "escolas chave" é um sistema de pontuação baseado nos resultados e na qualidade das escolas que as permitem estabelecer critérios para selecionar os alunos formandos da etapa anterior. O HSEE (High School Entrance Exam), ou zhongkao, como é popularmente chamado, é um exame classificatório que ordena os alunos para que possam ser selecionados pelas instituições de ensino médio. Embora existam métodos alternativos de seleção, a entrada no ensino médio continua até hoje profundamente fundamentada no resultado dos estudantes no exame. Além disso, caso o aluno não tenha conseguido um resultado satisfatório, o mesmo pode pagar (cerca de três a quatro vezes o valor das mensalidades acumuladas nos três anos de ensino médio) para ingressar na escola desejada, num método chamado school choice student (Zhang, 2016). Em outros termos, o acesso ao ensino médio de qualidade é extremamente concorrido, podendo ainda ser muito caro.

No caso do ensino superior, desde a década de 1990 a China inteira passou a cobrar mensalidades ou anuidades dos seus estudantes nas universidades (Zhang, 2016). Tanto o exame quanto a cobrança de mensalidades e taxas permanecem como gargalos ao acesso de parte significativa da população ao ensino superior, apesar da massiva ampliação promovida pelo governo chinês desde os anos 1990. Em 2015, mais de 40\% da população chinesa em 
idade cursava ou concluiu o ensino superior, contra pouco mais de $20 \%$ em 2007 (China Statistical Yearbook, 2016; Unesco).

Tendo em vista a trajetória do sistema educacional chinês e suas transformações recentes, é possível afirmar que o país teve relativo sucesso em frear as desigualdades na educação básica (primeiros nove anos de educação compulsória). A maior parte das desigualdades persistentes, e até crescentes, da educação chinesa dizem respeito às outras etapas, sobretudo o ensino médio ( $\mathrm{Li}, 2015)$. Há ainda diferenças significativas entre a educação oferecida em províncias com melhor desempenho econômico e nas demais (Liu, 2016). Além disso, o maior gap na educação do país ainda está na oposição entre a provisão rural e urbana.

As regiões privilegiadas pelo desempenho econômico das décadas de 1980 e 1990 gozaram de maior capacidade de financiamento da política educacional local tendo em vista o processo de descentralização promovido pelo Partido-Estado (Ngok, 2007; Liu, 2016). As políticas de expansão da educação chinesa em grande parte contribuíram para aprofundar essas disparidades, seja pelo fornecimento de recursos atrelados ao desempenho escolar, seja pela indexação dos gastos de educação ao crescimento econômico local. Além disso, ao estudar o impacto do aumento do investimento público em educação numa determinada região, observou-se que há uma tendência a aumentar o coeficiente de Gini no local. Isso porque na busca por resultados, os governos locais tendem a investir a maior quantidade de recursos nas melhores escolas, preterindo aquelas que carecem de financiamento e reforçando o círculo vicioso (Zhang, 2016). Algumas políticas de desenvolvimento regional e alguns planos para mitigar essas diferenças tem tomado forma na última década, em geral visando à região oeste do país (Du; Sun, 2016).

Assim como no caso das regiões mais pobres, a área rural do país ficou para trás na corrida da educação com o avanço das reformas. Além dos problemas comuns às áreas menos desenvolvidas, a parcela rural da população enfrenta uma barreira geográfica ao tentar ingressar no ensino médio e superior, devido à concentração geográfica da provisão desses serviços, ficando assim condicionados a um desempenho excepcional nos exames de acesso (Zhang, 2016).

Além disso, um dos problemas mais gritantes criado pelo sistema de hukou é o tamanho da população flutuante no país. A população migrante sem registro cresceu de forma acentuada desde os anos 2000 e se estabilizou em 2014 em torno de 250 milhões de pessoas. A política de contenção de fluxos migratórios institucionalizou uma população de segunda classe, sem acesso a serviços básicos como saúde e educação. Em relação a essas pessoas, o Partido-Estado tem adotado uma série de medidas que visam flexibilizar o hukou e garantir o acesso dessa parcela significativa da população aos serviços públicos básicos. No entanto, o governo chinês tem encontrado forte resistência por parte dos administradores dos colégios, que afirmam não ter recurso para absorver essa demanda. Como resultado, a cobrança de taxas abusivas e criação 
Isabela Nogueira, Fabianna Bacil, João Victor Guimarães

de empecilhos burocráticos continuam sendo barreiras significativas aos filhos de migrantes chineses (Gao, 2010; Wong et al., 2007).

Um resultado claro das desigualdades educacionais na China diz respeito à participação do país no teste PISA, organizado pela OCDE. Nas três participações chinesas, os resultados divergiram de acordo com a abrangência das províncias participantes. Em 2009 e 2012, a China surpreendeu o mundo ao obter a primeira colocação nas três categorias avaliadas. Em 2015, contudo, o país ficou em décimo lugar em ciências, sexto em matemática, e vigésimo sétimo em leitura. A diferença fundamental entre os exames está no fato de que nos dois primeiros anos apenas Xangai fez parte do teste, enquanto em 2015, Pequim, Guangdong e Jiangsu (todas regiões ricas) também foram avaliadas.

\section{0 estado de bem-estar social chinês: a caminho de qual regime?}

Esta seção busca realizar uma análise qualitativa visando comparar o EBES da China - usando como aproximação os sistemas de saúde e educação - com as tipologias consagradas para o caso ocidental e do leste asiático.

Conforme caracterizado anteriormente, o sistema de saúde chinês utiliza como instrumento principal o seguro social, reproduzindo nos benefícios a estratificação social que existe na sociedade - recapitulando Huang (2015), o sistema reproduz as clivagens do mercado de trabalho tanto a partir da posição que o indivíduo ocupa, quanto de acordo com o setor em que está empregado, além da região de origem e desenvolvimento econômico do local em questão. Além disso, é preciso considerar que o setor privado, embora esteja crescendo, possui papel pequeno no país do ponto de vista da oferta de seguros saúde - apesar de representar já quase metade da oferta de hospitais. Por fim, o Estado passou a ser mais atuante em decorrência da incapacidade de as famílias arcarem com os cuidados e custos médicos. Neste sentido, o caso chinês parece se aproximar mais do regime conservador-corporativista da tipologia de Esping-Andersen, que se caracteriza pela predominância dos seguros sociais como mecanismo primário de entrega de bem-estar, sendo seu objetivo principal a reposição de parte da renda dos indivíduos assegurados na eventualidade de concretização de algum risco social. Como os programas de seguro tendem a ser separados, o sistema resultante caracteriza-se pela fragmentação e heterogeneidade, com forte papel do status profissional na determinação do tipo de seguro - e consequentemente, benefícios - aos quais a pessoa tem direito, sendo que os trabalhadores industriais e servidores públicos são os mais favorecidos (Castles, 2010). O sistema educacional, por outro lado, não parece se encaixar unicamente em nenhum regime de Esping-Andersen. Embora o Estado seja fortemente atuante e os nove anos da educação básica compulsória sejam oficialmente gratuitos, há diversas barreiras que impedem seu acesso pela população inteira. Além disso, as políticas de desempenho, timidez dos programas focalizados e vícios do ensino médio fazem com que o sistema educacional reforce institucionalmente as clivagens da sociedade. 
No entanto, a utilização da tipologia ocidental para a classificação de países asiáticos tem muitas limitações, conforme explorado na segunda seção do artigo. Por exemplo, ao contrário do que se coloca com frequência no caso dos países ocidentais, Huang (2015) e Sander, Schmitt e Kuhnle (2012) destacam que o processo de maior provisão de bem-estar social pelo Estado não derivou do entendimento de que tais benefícios resultam dos direitos dos cidadãos, mas sim da busca por garantia da estabilidade social pelo governo. Afastando-se da análise ocidental, o modelo chinês até o começo da década de 2000 parece se enquadrar no regime produtivista de bem-estar, habitualmente associado aos países do leste asiático.

Recapitulando características do bem-estar produtivista, o governo chinês possui papel central na estrutura econômica como planejador e agente em várias esferas da produção ditas como próprias do mercado, tendo papel preponderante no objetivo de desenvolvimento econômico (Choi, 2012). No período que se estende desde o início das reformas econômicas introduzidas por Deng Xiaoping até o final da década de 1990, a subordinação do bem-estar ao objetivo de crescimento econômico é clara - ao longo desse período houve redução drástica do papel estatal na provisão de bem-estar para a população, sobretudo no caso da saúde. As reformas promoveram a flexibilização do mercado de trabalho e a redução de custos, visando impulsionar a competitividade na economia chinesa. Com isso, o modelo que até então era baseado nas unidades de trabalho e comunas rurais foi desfeito. A introdução do UEBMI em 1998 marca a forte seletividade da política de bem-estar, sendo atendidos apenas os funcionários do governo e os trabalhadores industriais urbanos, atores principais no processo de modernização e desenvolvimento da economia chinesa. Paralelamente, houve uma incrível expansão de estudantes no ensino superior chinês entre 1990 e 2000, sendo tal avanço motivado pelo entendimento por parte do Estado de que o ensino superior era um elemento vital no desenvolvimento do país, dado seu papel para formação de mão de obra qualificada (Ngok, 2007; Postiglione, 2016). Assim, fica clara a subordinação do sistema de proteção social ao objetivo de crescimento econômico, e o sistema chinês demonstra sua semelhança ao regime produtivista asiático ao ligar a política social ao mercado de trabalho.

A transição da economia socialista para uma baseada no mercado significou a emergência de novos riscos sociais - por exemplo, a migração de enormes massas de moradores rurais para as cidades enquanto os mesmos permaneceram excluídos dos programas de bem-estar vigentes; a flexibilização do mercado de trabalho levou à perda da estabilidade vitalícia do emprego e maior vulnerabilidade da população à flutuação inerente à economia de mercado; o foco no crescimento do PIB acarretou o aumento da desigualdade social na população chinesa. Com o consequente aumento da agitação social, o governo chinês precisou reestruturar a relação entre Estado, mercado e sociedade civil na provisão de bem-estar, de modo a incluir parcelas maiores da população e garantir a estabilidade social necessária para a continuidade do processo de desenvolvimento econômico. $\mathrm{O}$ objetivo de construção de uma "sociedade harmoniosa", assim, deve ser compreendido como um instrumento para a manutenção da legitimidade do Partido e subordinado à estratégia econômica (Sander; Schmitt; Kuhnle, 2012). O aumento da desigualdade, a piora do status da saúde da população e o 
aumento da instabilidade social trouxeram mudanças nas prioridades do governo, que deixaram de ser apenas o crescimento econômico e passaram a incluir a busca por uma sociedade mais equitativa, marcada na área de saúde pela introdução do NRCMS e do URBMI, e na área da educação pelos planos de universalização do ensino compulsório, trazendo poucos elementos preliminares do modelo redistributivo no EBES chinês a partir da década de 2000.

\section{Considerações finais}

Apesar do avanço conquistado com a universalização da cobertura dos seguros de saúde e dos nove anos de educação básica compulsória e gratuita, a China ainda precisa superar diversos problemas para que sua população desfrute de um sistema de proteção social robusto. A desigualdade do nível de generosidade dos programas de saúde implica em um universo de atendimento de saúde radicalmente distinto para populações com diferentes registros de moradia e distintas posições no mercado de trabalho. Na educação, a desmercantilização é apenas parcial, e a pré-escola e a universidade vão se consolidando como espaços pagos, além de o ensino médio assistir a uma disseminação de instrumentos paralelos privados ou de pagamento de taxas extras para facilitar o acesso às escolas de ponta.

O histórico gap urbano-rural e a distância entre trabalhadores do setor formal e informal estão sendo reproduzidos via um viés pró-mercado de trabalho formal e urbano na condução da política social. Outra questão é o alto grau de descentralização das despesas das políticas sociais, que reproduzem as desigualdades inter-regionais e mantêm marginalizados os trabalhadores migrantes e suas famílias. Assim, ao mesmo tempo em que houve a expansão de cobertura dos seguros sociais de saúde e universalização do ensino básico ao longo do período analisado, elas vieram acompanhadas pelo aprofundamento das desigualdades via a institucionalização de uma política social heterogênea.

Baseando a análise nos sistemas de saúde e educação, o sistema de proteção social que se desenha no caso chinês se aproxima especialmente do modelo produtivista na tipologia do leste asiático. Contudo, há diversas limitações ao analisar o EBES de um país a partir apenas dos sistemas de saúde e educação. Primeiramente, as políticas sociais de um Estado enquadram diversos outros aspectos que não são contemplados no presente trabalho, como as transferências e outros serviços sociais. Além disso, tais sistemas configuram a "exceção" em alguns países - caso do Canadá, por exemplo, que apesar de poder ser incluídos no regime liberal de Esping-Andersen, possui sistemas públicos universais de saúde e educação básica. Assim, embora tal análise seja útil para resultados preliminares, é preciso aprofundar o estudo incluindo as demais áreas de bem-estar, sobretudo educação e previdência. Por fim, como esse processo de construção de um EBES começou muito recentemente na China, após anos 2000, e segue em intensa mudança, o levantamento feito aqui é seguramente uma caracterização parcial de um processo em construção. Neste sentido, é fundamental seguir com as pesquisas também na área de saúde e educação, acompanhando as mudanças, de forma a alcançar uma caracterização mais abrangente do tipo de EBES que está sendo desenvolvido na China. 
A caminho de um estado de bem-estar social na China? Uma análise a partir dos sistemas de saúde e de educação

\section{Referências bibliográficas}

ARTS, Wil; GELISSEN, John. Three worlds of welfare capitalism or more? A state-of-the-art report. Journal of European Social Policy, v. 12, n. 2, p. 137-158, 2002.

BAMBRA, Clare. Going beyond the three worlds of welfare capitalism: regime theory and public health research. Journal Epidemiol Community Health, v. 61, n. 12, p. 1098-1102, 1997.

BANCO MUNDIAL. China long-term issues and options. 1985. Disponível em: https://goo.gl/iQuqYz. Acesso em: out. 2016.

BANCO MUNDIAL. World Development Indicators. Disponível em: https://goo.gl/kSSNIT. Acesso em: out. 2016.

BONOLI, Giuliano. Classifying welfare states: a two-dimension approach. Journal of Social Policy, v. 26, n. 3, p. 351-372, 1997.

CASTLES, Francis G. Comparative public policy: patterns of post-war transformation. Cheltenham: Edward Elgar, 1998.

CASTLES, Francis G. The english-speaking countries. In: CASTLES, Francis et al. (Ed.). the Oxford handbook of the welfare state. Oxford: Oxford University Press, 2010. p. 639-644.

CHAN, Raymond K. H.; LIN, Ka. Repositioning three models of social policy with reference to East Asian welfare systems. International Social Work, v. 58, n. 6, p. 831-839, 2013.

CHAN, Chak. K.; NGOK, King L.; PHILLIPS, David. Social policy in China: development and well-being. Bristol: Policy Press, 2008.

CHEN, Tianhong; TURNER, John A. Fragmentation in social security old-age benefit provision in China. Journal of Aging \& Social Policy, v. 27, n. 2, p. 107-122, 2015.

CHOI, Young J. End of the era of productivist welfare capitalism? diverging welfare regimes in East Asia. Asian Journal of Social Science, v. 40, n. 3, p. 275-294, 2012.

CUI, Ernan. The end of the preschool boom. Ideas. 2017. Disponível em: https://research.gavekal.com/. Acesso em: dez. 2017.

DU, Yuhong; SUN, Zhijun. Research on compulsory education financing in China. Pequim: Springer, 2016.

ESPING-ANDERSEN, Gosta. The three worlds of welfare capitalism. Princeton: Princeton University Press, 1990.

EY. The rise of private health insurance in China: consumer demand presents huge opportunities and risks. 2016. Disponível em: https://goo.gl/FwtjIt. Acesso em: nov. 2016.

FERRERA, Maurizio. The 'southern' model of welfare in social Europe'. Journal of European Social Policy, v. 6, n. 1, p. 17-37, 1996. 
Isabela Nogueira, Fabianna Bacil, João Victor Guimarães

GAO, Qin. The redistributive nature of the Chinese social benefit system: progressive or regressive? The China Quarterly, 201, p. 1-19, 2010.

HSIAO, William C. The political economy of Chinese health reform. Health Economics, Policy and Law, v. 2, n. 3, p. 241-249, 2007.

HUANG, Xian. Expansion of Chinese social health insurance: who gets what, when and how? Journal of Contemporary China, v. 23, n. 89, p. 923-951, 2014.

HUANG, Xian. Four worlds of welfare: understanding subnational variation in Chinese social health insurance. The China Quarterly, 222, p. 449-474, 2015.

KERSTENETZKY, Celia L. Democracia e welfare. Niterói: UFF/CEDE, 2011. (Texto para Discussão, n. 37). p. 86-113. Disponível em: https://goo.gl/LFHVLo. Acesso em: dez. 2015.

KERSTENETZKY, Celia L. Welfare state e desenvolvimento. Dados, v. 54, n. 1, p. 129-156, 2011.

KERSTENETZKY, Celia L.; KERSTENETZKY, Jaques. O Estado (de bem-estar social) como ator do desenvolvimento: uma história das ideias. Dados, Rio de Janeiro, v. 58, n. 3, p. 581-615, 2015.

KURTZIG, J.; WANG, N. Public health, private gains. China Economic Quarterly, v. 21, n. 1, p. 24-31, 2017.

KWON, Huck-ju. Transforming the developmental welfare states in East Asia. Development and Change, v. 36, n. 3, p. 477-497, 2005.

KWON, Huck-ju; MKANDAWIRE, Thandika; PALME, Joakim. Introduction: social policy and economic development in late industrializers. International Journal of Social Welfare, v. 18, n. s1, p. S1-S11, 2009.

LEE, Sophia S-Y. Development of the 'productivist' welfare regimes in Japan and Korea. In: HIGO, Masa; KLASSEN, Thomas R. (Ed.). Retirement in Japan and South Korea: the past, the present and the future of mandatory retirement. London / New York: Routledge, 2015. p. 30-47.

LEIBFRIED, Stephan. Towards a European welfare state? On integrating poverty regimes into the European Community. In: FERGE, Z.; KOLBERG, J. E. (Ed.). Social policy in a changing Europe. Frankfurt am Main: Campus Verlag, 1992.

LI, Chunling. Trends in educational inequality in different eras (1940-2010) - a re-examination of opportunity inequalities in urban-rural education. Chinese Education and Society, v. 48, n. 3 , p. $163-182,2015$.

LI, Mianguan; WALKER, Robert. Targeting social assistance: Dibao and institutional alienation in rural China. Social Policy \& Administration, 2016. Disponível em: https://goo.gl/5cZcEu. Acesso em: jan. 2017. 
A caminho de um estado de bem-estar social na China? Uma análise a partir dos sistemas de saúde e de educação

LI, Haitao et al. Comparision of perceived quality amongst migrant and local patients using primary health care delivered by community health centers in Shenzhen, China. BMC Family Practice, v. 15, n. 76, p. 2014.

LIU, Yuan. Reforming China's urban health insurance system. Health Policy, v. 60, n. 2, p. 133-150, 2002.

LIU, Ye. Higher education, meritocracy and inequality in China. London: Springer, 2016.

LIU, GG. Building a national health system. China Economic Quarterly, v. 21, n. 1, p. 16-23, 2017.

MEDEIROS, Carlos A. S.; NOGUEIRA, Isabela. Uma abordagem estruturalista das desigualdades de renda na China contemporânea. Revista Tempo do Mundo, v. 3, n. 3, p. 99$121,2011$.

MENG, Qingyue et al. Consolidating the social health insurance schemes in China: towards an equitable and efficient health system. The Lancet, v. 386, n. 10002, p. 1484-1492, 2015.

MIYAMOTO, Taro. Dynamics of the Japanese welfare state in comparative perspective: between 'three worlds' and the developmental State. The Japanese Journal of Social Security Policy, v. 2, n. 2, p. 12-24, 2003.

MÜLLER, Armin. Hukou and health insurance coverage for migrant workers. Journal of Current Chinese Affairs, v. 45, n. 2, p. 53-82, 2016.

NATIONAL BUREAU OF STATISTICS OF CHINA. China Statistical Yearbook 2015. Pequim. Disponível em: https://goo.gl/ezGrFM. Acesso em: out. 2016.

NATIONAL BUREAU OF STATISTICS OF CHINA. China Statistical Yearbook 2016. Pequim. Disponível em: http://www.stats.gov.cn/tjsj/ndsj/2016/indexeh.htm. Acesso em: jul. 2017.

NGOK, Kinglun. Chinese education policy in the context of decentralization and marketization: evolution and implications. Asia Pacific Education Review, v. 8, n. 1, p. 142$157,2007$.

PIERSON, Christopher. Beyond the Welfare State? - the new political economy of welfare. Cambridge: Polity Press, 1991.

POSTIGLIONE, Gerard A. (2006). Social change in China: inequality in a market economy. London / New York: Routledge, 2015.

POSTIGLIONE, Gerard A. Foreword. In: GUO, Shibao; GUO, Yan (Ed.). Spotlight on China: changes in education under China's market economy. Roterdã: Sense Publishers, 2016.

OCDE. Education in China: a snapshot. 2016. Disponível em: https://www.oecd.org/china/publicationsdocuments/reports/. Acesso em: out. 2017. 
Isabela Nogueira, Fabianna Bacil, João Victor Guimarães

SANDER, Anne; SCHMITT, Christopher; KUHNLE, Stein. Towards a Chinese welfare state? Tagging the concept of social health security in China. The Perspective of the World Review, v. 4, n. 2, p. 9-35, 2012.

THE COMMON WEALTH FUND (2015). International profiles of health care systems. 2016. Disponível em: commonwealthfund.org. Acesso em: jan. 2017.

UNDP China / Development Research Center of the State Council of China. Social innovation for inclusive human development. China National Human Development Report, 2016. China Publishing Group Corporation, China Translations and Publishing House, 2016. Disponível em: https://goo.gl/zCtSE0. Acesso em: nov. 2016.

UNESCO-UIS. Instituto de Estatística da Organização das Nações Unidas para a Educação, Ciência e Cultura. Disponível em: http://data.uis.unesco.org/. Acesso em: nov. 2017.

WANG, Yanping et al. Under-5 mortality in 2851 Chinese counties, 1996-2012: a subnational assessment of achieving MDG 4 goals in China. The Lancet, v. 387, n. 10015, p. 273-283, 2016.

WONG, Daniel F. et al. Rural migrant workers in urban China: living a marginalised life. International Journal of Social Welfare, 16, p. 32-40, 2007.

YU, Hao. Universal health insurance coverage for 1.3 billion people: what accounts for China's success? Health Policy, v. 119, n. 9, p. 1145-1152, 2015.

ZHANG, Yu. National college entrance exam in China: perspectives on education quality and equity. Pequim: Springer, 2016.

ZHANG, Saijun; CI, Qinying; ZHAN, Min. Public assistance in urban and rural China: a tale of two stories. International Journal of Social Welfare, v. 26, n. 4, p. 303-313, 2017.

ZHU, Minmin. et al. The influence of health insurance towards accessing essential medicines: the experience from Shenzhen labor health insurance. Health Policy, v. 88, n. 2, p. 371-380, 2008 . 